\section{Библиографический список}

1. Агроклиматические ресурсы Саратовской области. Л., 1970. 123c.

2. Пряхина С.И., Скляров Ю.А., Левицкая Н.Г. Агрометеорологические прогнозы: Учеб.-метод. пособие. 2-е изд., доп. Саратов, 2006. 72 с.
3. Кабанов П.Г. Погода и поле. Саратов, 1975. 235 с.

4. Пряхина С.И. Структура и продолжительность климатических сезонов г. Саратова. М., 1966. 10 с. Деп. в ВИНИТИ. №1524-В96.

5. Левицкая Н.Г. Повышение эффективности использования биоклиматического потенциала агроландшафтов Саратовского Правобережья: Автореф. дис. ... канд. с.-х. наук. Саратов, 2003. 19 с.

УДК 528 (470.44)

\title{
КАРТОГРАФИЧЕСКАЯ МОДЕЛЬ ГЕОЭКОЛОГИЧЕСКОЙ ОЦЕНКИ ТЕРРИТОРИИ
}

\section{В.К. Штырова, О.Е. Нестерова \\ Саратовский государственный университет, кафедра геоморфологии и геоэкологии E-mail: Nesterova@sgu.ru}

В статье рассматривается методика создания картографической модели геоэкологического состояния территории. Приводится поэтапное описание процесса создания карт и их назначение. Обосновывается важность использования рельефа в качестве объекта картографирования при создании геоэкологической карты.

Ключевые слова: картографическая модель, геоэкология, рельеф, природно-техногенные процессы, природопользование, легенда, способы изображения.

\section{Model of the Geoecological Assessment of a Territory}

\section{V.K. Shtyrova, O.E. Nesterova}

In this article the method of creation a cartographic model of the geoecological situation of a territory is considered. The description of maps creation and their purpose is given. The necessity of relief using as the object of mapping in the creating a geoecological map is justified.

Key words: cartographic model, geoecology, relief, natural-technogenic processes, wildlife management, legend, ways of the image.

Комплексное картографирование определяется К.А. Салищевым как метод многостороннего и целостного показа действительности картографическими средствами.

Комплексное системное картографирование может являться в этой связи основой комплексной геоэкологической оценки территории.

Сущность геоэкологического картографирования заключается в системном отображении, во-первых, комплекса природных и техногенных факторов в их взаимосвязи, динамики и, вовторых, в организации самого картографирования.

Особенности этого вида картографирования сводятся к следующим принципам:

1) основой геосистемного исследования служит картографическая модель геосистемы, соответствующая задачам, тематике, уровню генерализации, масштабу исследования;

2) основное внимание сосредотачивается на

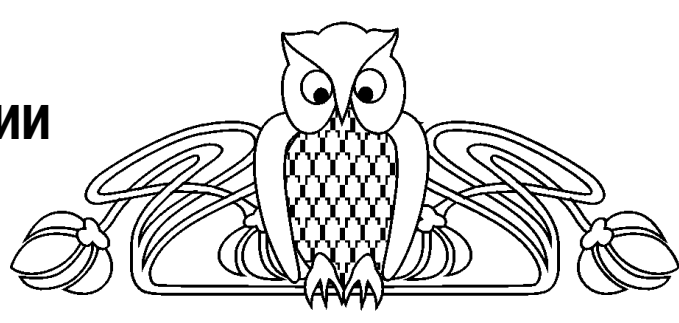

выявлении и картографировании системообразующих связей;

3) вслед за этим выясняется пространственная структура геосистемы, ее организация, динамика, функционирование, изучаются процессы обмена веществом и энергией, анализируются возможности управления геосистемой.

С помощью картографических моделей, по мнению А.М. Берлянта, осуществляются упорядоченный сбор и обработка информации, ведение дистанционных наблюдений, регистрация состояния, динамики и функционирования геосистем. Основными документами для исследований служат системы карт. В соответствии с поставленной целью составляют карты различной тематики, разновременные, разного масштаба и степени синтеза. При этом речь идет не просто об использовании больших и разнообразных комплектов тематических карт, а об оптимальном наборе для каждого конкретного случая [1].

Единой научно-обоснованной методики подобного картографирования пока не разработано, но существует достаточно много региональных схем.

Предложенная нами методика геоэкологической оценки территории построена на наличии большого фактического материала, выводит на составление картографической модели геоэкологической обстановки и апробирована на территориях Новоузенского, Саратовского, Советского и других районов Саратовской области, нефтегазоносных месторождениях Крайнего Севера.

Основой картографического решения поставленной задачи являлись топографические и тематические карты масштабов 1:100 000, 1:200 000, 1:500 000.

Создание картографической модели осуществлялось поэтапно следующим образом.

Первый этап включает в себя сбор и обработку информации, характеризующей совре- 
менное состояние природной среды и ресурсов, отражает пространственное положение природных комплексов, генезис, структуру, условия, оказывающие влияние на возникновение и развитие неблагоприятных экзогенных процессов. Современный рельеф, являясь основой хозяйственной деятельности и средой проживания, служит каркасом ландшафта территории, оказывает влияние на характер изменения других физико-географических условий и определяет в значительной степени положение ареалов распространения и пути миграции загрязнителей. От него зависит поверхностный и подземный сток.

Поэтому обязательным на втором этапе является составление по топографической основе геоморфологической карты, отражающей основные морфологические элементы: водораздельные пространства, склоны и речные долины. Морфологические элементы являются динамичными образованиями и достаточно четко обнаруживают взаимные связи. Антропогенные воздействия на этих территориях активизируют проявления таких экзогенных процессов, как линейная эрозия, оползни, дефляция, абразия берегов, подтопление и пр. Поэтому выделенные морфологические элементы становятся объективным геоэкологическим экраном при проектировании или сооружении объектов техносферы.

Современное состояние основных элементов рельефа отражает серия морфометрических карт. К ним следует отнести карты горизонтального и вертикального расчленения, карту углов наклона земной поверхности и экспозиции склонов, карту показателей интенсивности глубинной эрозии.

Характер горизонтального расчленения территории определяется активностью эрозии, развитием и становлением речной (эрозионной) сети. Составлением карты горизонтальной расчлененности преследуется цель указать место и действие эрозионного фактора, определить участки его максимальной активности, т.е. места, где допустимость техногенной нагрузки должна строго регламентироваться «эрозионной опасностью» (размывом, оврагообразованием, подтоплением, высоким паводком и т.д.) [2].

Вертикальную расчлененность рельефа большинство исследователей рассматривают в качестве отражения характера тектонических движений (новейших и современных), дифференцируя их на движения положительного и отрицательного знаков, выделяя на земной поверхности положительные и отрицательные разнопорядковые структурные формы - поднятия и опускания. Данная карта, находясь, как правило, во взаимосвязи с горизонтальным расчленением земной поверхности, определяет «темп денудации» и интенсивность: на водоразделах - это скорость выветривания и подготовка почвогрунтовых масс к сносу; на склонах - интенсивность перемещения масс в речные долины; в долинах - скорость переноса осадков к местам аккумуляции.
Если геоморфологическая карта, составленная по принципу выделения морфологических элементов, отражает местоположение рельефообразующих процессов, пространственную дифференциацию их границ, то карта вертикального расчленения показывает относительный характер интенсивности процессов денудации. Этот показатель, выраженный изолинейно, дает возможность локализовать место и действие геоморфологического фактора и выразить относительную величину его активности.

Карта углов наклона земной поверхности и экспозиции склонов указывает местоположение углов наклона местности, разделенных на различные интервалы в зависимости от картографируемой территории. Карта составляется с целью получения дополнительного, более конкретного материала о характере склоновой денудации [2].

Водораздельные пространства являются областями топографически несмещенных почвенногрунтовых масс. Склоны, напротив, - это те поверхности, по которым снос и транзит обломочных масс осуществляется активно и находится в зависимости от угла наклона местности. Склоновые процессы протекают в виде плоскостного смыва, делювиального сноса, обвально-осыпных, оползневых и прочих явлений. Денудация - деструктивная сила, она формирует состояние «геоэкологической неустойчивости». Таково основное содержание всей серии морфометрических карт, являющихся производными от геоморфологической. Эти карты должны выполнить функцию поиска оптимальных точек для размещения в дальнейшем техногенных объектов.

В процессе создания картографической модели геоэкологического состояния важным является составление карты современных рельефообразуюших проиессов. За основу берется геоморфологическая карта, с помощью которой выявляются участки развития преобладающих экзогенных процессов сноса, перемещения и аккумуляции, которые совершались в историческое время и проявляются в современную эпоху. Рельефообразующие процессы - гравитационные, эрозионные, аккумулятивные, эоловые и т.д. - это процессы, происходящие на земной поверхности и производящие определенную работу по перестройке ее внешнего облика путем изменения (в той или иной степени) форм рельефа или создания новых [2].

В процессе наблюдения за взаимосвязью между распространением генетических типов рельефа и рельефообразующими процессами вскрываются интересные особенности территории.

На водораздельных поверхностях развивается выветривание, идет накопление элювия. На склонах водораздельных поверхностей формируются плоскостной смыв и линейная эрозия, т.е. комплекс денудационных процессов. На флювиальном рельефе происходит процесс аккумуляции. 
Современные процессы рельефообразования являются одним из показателей изменения окружающей среды, ее реакции на хозяйственную деятельность человека, которую нельзя оценить однозначно.

Первые два этапа картографирования логически связаны между собой. Итоговой картой здесь должна явиться карта суммарных показателей интенсивности денудациионных и аккумулятивных процессов, которая выявляет, образно говоря, «направление главного удара», где нагрузка на ландшафты уже достаточно велика и без вмешательства человека. Эти области достаточно четко выделяются на карте и связаны с водораздельными поверхностями и склонами с углами наклона $3-5^{\circ}$ и более.

Современная динамика геоморфологических процессов должна быть охарактеризована через суммарный показатель интенсивности, с одной стороны, процессов денудации, а с другой - аккумулятивных процессов. Каждый из анализируемых процессов оценивается в условных баллах. Денудационные процессы, имеющие деструктивный характер, оцениваются условными баллами со знаком минус, аккумулятивные - со знаком плюс. Алгебраическая сумма показателя интенсивности исчисляется по заданной системе квадратов и определяет суммарный показатель интенсивности. Этот показатель оценивает условия, при которых действуют деструктивные процессы и противоположные им процессы аккумуляции. Первые при техногенных воздействиях должны оцениваться как неблагоприятные для сохранения геосистем, аккумуляция, напротив, определяет устойчивость соответственных ландшафтов, подчиняясь процессу саморегуляции. Данная карта необходима для оценки экологической обстановки.

Tретий этап характеризует степень и виды антропогенного или техногенного преобразования природной среды, отображаемые на картах состояния окружающей среды, антропогенной нагрузки и типов природопользования.

Карта состояния окружающей среды отражает экологическую обстановку территории. В содержании трех разделов карты необходимо показать качество природной среды и состояние природных ресурсов, особо охраняемые природные территории и памятники природы, влияние на окружающую среду хозяйственных объектов. Хорошим дополнением будет информация о состоянии поверхностных и подземных вод, их загрязненности различными элементами, очагах загрязнения.

В разделе, посвященном земельным ресурсам, характеризуются состояние почвенного покрова и негативные проявления, вызванные сельскохозяйственной деятельностью (степень проявления водной и ветровой эрозии), антропогенно активизированные современные экзогенные процессы (интенсивный размыв берегов, оживле- ние оползневых процессов), вторичное засоление орошаемых земель и др.

В разделе о влиянии хозяйственных объектов на окружающую среду показывается сеть магистральных трубопроводов, места пересечения их с водными артериями, транспортными магистралями, между собой, отмечаются крупные опасные промышленные объекты, селитебные территории и пр.

Систематическое картографическое слежение за состоянием природной среды, ее изменениями, обусловленными хозяйственной деятельностью, составит одно из звеньев экологического мониторинга.

Карта антропогенной нагрузки. Одной из частных карт, выполняемых при создании картографической модели геоэкологической обстановки, является карта антропогенной нагрузки. Она содержит информацию о результатах воздействия антропогенной деятельности на литогенную основу и ландшафты. При составлении карты проводится отбор, анализ и систематизация данных о различных видах антропогенной нагрузки.

С целью упорядочения обильного материала производится инвентаризация объектов техногенной нагрузки, относящихся к различным геотехническим системам: геогорнотехнической, гидротехнической, градопромышленной, агрогидромелиоративной, агролесомелиоративной и др. [3].

К геогорнотехнической системе относятся газо- и нефтепромыслы, карьеры как действующие, так и отработанные, газохранилища, станции перекачки газа и др. В местах расположения перечисленных объектов обострение экологической опасности усиливается сопутствующими антропогенно возбужденными и антропогенно активизированными геологическими и гидрогеологическими процессами - линейной и плоскостной эрозией, суффозией и пр.

К объектам гидротехнической системы относятся водохранилища, пруды, плотины. Массовое запруживание мелких рек и балок приводит к резкому подъему грунтовых вод и самоподтоплению близкорасположенных населенных пунктов.

В блок агромелиоративной системы вносят магистральные оросительные каналы, инженернотехнические сооружения, орошаемые массивы.

К блоку градопромышленной системы относятся селитебные территории, свалки бытовых и промышленных отходов, скотомогильники и т.д.

Геотехничекая линейно-транспортная система включает в себя крупные железнодорожные и автомобильные магистрали, насыпи под них, дамбы, выемки, продуктопроводы, ЛЭП.

Эти объекты менее опасны, но они являются составной частью антропогенного пресса на ландшафты. Прокладка транспортных магистралей ухудшает условия жизнеобитания многих видов животных, для создания насыпей и дамб срезается большое количество грунтов, в том числе и пло- 
дородных почв, приподнятые объекты приводят к перераспределению поверхностного стока.

Объектами агролесомелиоративной системы являются лесополосы, которые часто располагаются вдоль автомобильных дорог, лесопитомники, опытные площадки. При составлении карт антропогенной нагрузки важно иметь качественные аэро- и космоснимки и, что еще лучше, несколько залетов разных лет. Можно составлять и покомпонентные карты для различных видов нагрузки (например, площадной нагрузки или линейных сооружений). Имеется в виду то, что различный техногенез ведет к проявлению совершенно иных современных физико-геологических процессов, соответственно изменяется ход восстановительной динамики геосистем.

Карта типов природопользования. Для составления данной карты целесообразно применить классификацию С.П. Горшкова [4]. В ней охарактеризовано 12 наиболее распространенных типов природопользования. Приводим некоторые их них.

1. Сельскохозяйственное природопользование, куда входят сельхозугодья, пастбища, выгоны, суходольные сенокосы, огороды, сады, молочные комплексы по откорму скота, производство овощной продукции и пр.

2. Урбано-промышленное или коммунальное природопользование, к которому относят села и поселки городского типа.

3. Водохозяйственное природопользование. К этому типу относятся реки и различные по форме и размерам пруды как естественного, так и искусственного происхождения, водохранилища.

4. Коммуникационно-транспортное или пространственно-увязывающее природопользование, включающее линии электропередач, железные дороги, автомобильные дороги, магистральные нефтегазопроводы.

5. Хранилищно-складское природопользование - склады, амбары, элеваторы, станции подземного хранения газа, управления производственнотехнической комплектации и пр.

6. Добыча полезных ископаемых, или горнопромышленное природопользование, к которому относятся промысловые скважины, карьеры.

7. Лесохозяйственное природопользование, куда относятся лесхозы, места рубок леса, сплава лесополосы и др.

8. Фабрично-заводское природопользование.

9. Отходосвалочное природопользование, которое включает свалки, места захоронения отработанных материалов, скотомогильники и т.д.

Карты типов природопользования необходимы при разработке мероприятий по поддержанию экологического равновесия природной среды и рационального природопользования.

Четвертый эman картографирования подводит к отражению мероприятий по соблюдению допустимых нагрузок на природные комплексы и составлению картографической модели по под- держанию естественного равновесия природных комплексов в результате интенсивного использования земель.

В этом смысле обобщающей картой является геоэкологическая, суммирующая все природные и техногенные показатели.

В настоящее время в геоэкологическом картографировании отсутствуют согласованные представления о содержании геоэкологической карты, да и сам термин «геоэкология» разные исследователи трактуют неоднозначно.

Особенностью нашего подхода при составлении среднемасштабной геоэкологической карты является то, что в качестве «первичного фона» (или объекта картографирования) выступают рельеф и создающие его рельефообразующие процессы как экологический фактор «среды возникновения» и его техногенные трансформации [5].

Современные процессы рельефообразования являются одним из показателей изменения окружающей среды, ее реакции на хозяйственную деятельность человека, которую нельзя оценить однозначно.

При составлении геоэкологической карты среднего масштаба в качестве типовых единиц предлагается выделять геоэкологические комплексы, которые представляют собой территорию с общими ландшафтными условиями (рельефом, геологическим строением, климатом, почвеннорастительным покровом и пр.) и одинаковой экологической обстановкой, сформировавшейся в результате однотипного антропогенного воздействия [6].

Карта состоит из семи разделов.

I-II разделы. В классификации комплексов в основном выделяются 5 классов: элювиальный, трансэлювиальный, аккумулятивный, аквальный, трансаквальный.

К элювиальному классу относятся генетически однородные поверхности, в формировании которых преобладают процессы денудации и постепенного выноса продуктов выветривания. Это водораздельные поверхности (плакоры), вершины.

Трансэлювиальный класс объединяет территории, характеризующиеся процессами постоянного перемещения вещества под действием гравитационных сил - класс склонов.

В аккумулятивный класс входят участки земной поверхности, где происходит постоянное накопление пассивных отложений, приходящих в движение лишь в зонах действия линейной эрозии - это поверхности террас, котловины, подножия склонов.

Аквальный класс объединяет водные пространства, подразделяющиеся на два подкласса: субаквальный - озера, водохранилища и т.п. и трансаквальный - русловые урочища, балочные долины.

III раздел. Виды однородных поверхностей выделяются по генезису форм рельефа: денуда- 
ционные, флювиальные, флювиогляциальные, аккумулятивные, морские, озерные, эоловые, биогенные, антропогенные (техногенные) и др.

IV раздел. На общей геоэкологической карте необходимо показать результаты проявления главных процессов, протекающих в настоящее время в литосфере, гидросфере и атмосфере с их количественной характеристикой, выделением аномальных участков, превышающих допустимые нормы для существования и жизнедеятельности живых организмов и человека, выраженных в предельно допустимых величинах. Необходимо показать все генетическое многообразие природных процессов и условий, определяющих геоэкологическую обстановку территории, а также процессов и объектов, связанных с деятельностью человека, отрицательно сказавшихся на среде обитания. Особенное внимание обращается на антропогенно-возбужденные процессы - эрозию, абразию, оползни, суффозионно-просадочные, карст, подтопление населенных пунктов, переработку берегов, дефляцию, засоление зоны аэрации, заболачивание и др.

$\mathrm{V}$ раздел. К геоэкологическим факторам, характеризующим состояние окружающей среды, на карту следует нанести линейные зоны повышенного напряженного состояния земной коры или разрывные нарушения, по которым происходит резкое изменение тех или иных компонентов геологической либо геоморфологической среды, крупных техногенных объектов.

VI раздел легенды-матрицы отражает использование территории и те нарушения природных условий, которые его сопровождают, или степень антропогенной изменчивости ландшафтов. Техногенная нагрузка является одним из основных факторов, определяющих состояние окружающей среды в Саратовской области. Это густая дорожнотранспортная сеть, магистральные трубопроводы, эксплутационные скважины, карьеры, отвалы, опасные хозяйственные объекты, мелиоративные и гидротехнические сооружения, лесополосы, крупные животноводческие комплексы и др.

VII раздел. В нем отображаются мероприятия по охране и преобразованию природы. Это особо охраняемые территории (заказники, заповедники, памятники природы, предприятия по очистке сточных вод, пылегазоочистные сооружения, орошаемые земли, места акклиматизации и реакклиматизации животных, рекультивированные карьеры, базы отдыха).

Таков предполагаемый, на наш взгляд, стиль построения легенды к общей геоэкологической карте. Естественно, при широком обсуждении ее содержание может быть дополнено и уточнено, но должен остаться неизменным генетический принцип ее построения.

Способы изображения различных компонентов геоэкологической среды не менее существен- ны при составлении синтетической карты, чем их классификация и систематика. От правильно подобранных способов изображения зависит читаемость карты, а также выделение главных экологических показателей для каждой из территорий.

На образце авторского оригинала геоэкологической карты Саратовской области масштаба 1:500 000 в основе лежит показ генетически однородных поверхностей, приуроченных к 5 классам, способом качественного фона. Для элювиального класса выбран светло-коричневый фон, для трансэлювиального - желтый, для аккумулятивных поверхностей - светло-зеленый цвет, для аквального класса - светло-голубой и голубой цвета.

Ареалами и буквенными индексами различного цвета показываем площади проявления разнообразных современных экзогенных процессов.

Тектонические нарушения изображаются линейными знаками малинового цвета.

Все многочисленные техногенные объекты переносятся на геоэкологическую карту с топографической и обозначаются черным цветом. Для показа различных опасных объектов и процессов применены штриховка, крап, внемасштабные знаки, изолинии и другие средства изображения красного цвета. Обилие таких средств показа дает возможность оценить интенсивность порой негативного воздействия человека на окружающую среду, экологическую обстановку.

Охраняемые объекты и базы отдыха изображаются внемасштабными условными знаками и другими способами.

Предстоит серьезная кропотливая работа над этими способами изображения, так же как и над системой условных обозначений.

Изложенное выше поможет более конкретно и точно решать задачу создания картографической модели геоэкологической оценки территории.

\section{Библиографический список}

1. Селиверстов Ю.П. Основы геоэкологии: Учебник / Под ред. В.Г. Морачевского. СПб., 1994. 351 с.

2. Спиридонов А.М. Основы общей методики полевых геоморфологических исследований и геоморфологического картографирования. М., 1970. 455 с.

3. Брылев В.А., Агарков Е.В. Принципы и методы составления среднемасштабной областной экологической карты (на примере Волгоградской области): Метод. рекомендации. Волгоград, 1992.

4. Зворыкин К.В. Географическая концепция природопользования // Вестн. Моск. ун-та. Сер. География. 1993. № 3. C. 3-16.

5. Реймерс Н.Ф. Природопользование: Словарь-справочник. М., 1990.639 с.

6. Штырова В.К. Геоэкологичекая карта: содержание, принципы и методы ее создания // Изв. Сарат. ун-та. Нов. cep. 2004. Т.4, вып. 1-2. С. 164-167. 